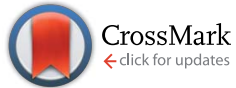

Cite this: RSC Adv., 2017, 7, 1724

Received 16th October 2016

Accepted 13th December 2016

DOI: 10.1039/c6ra25314h

www.rsc.org/advances

\section{Electrospray biodegradable microcapsules loaded with curcumin for drug delivery systems with high bioactivity $\dagger$}

\begin{abstract}
Zhuoxian Mai,,$^{\mathrm{a}}$ Jiali Chen, $\dot{t}^{\mathrm{b}}$ Ting $\mathrm{He},{ }^{\mathrm{a}}$ Yang Hu,${ }^{\mathrm{a}}$ Xianming Dong, ${ }^{\mathrm{a}}$ Hongwu Zhang, ${ }^{\text {tb }}$ Wenhua Huang, ${ }^{\text {b }}$ Frank Ko*c and Wuyi Zhou ${ }^{\star a}$

In the present work, polylactic acid (PLA) microcapsules as novel drug delivery systems were successfully fabricated by one-step processing using an electrospray technique. Curcumin (Cur) was chosen as model drug with satisfactory loading capacity (LC\%) and entrapment efficiency (EE\%) greater than $95 \%$. By judiciously adjusting spinning solvents, flow rates, polymer and drug concentrations, the monodisperse and spherical structures of Cur/PLA microcapsules observed using scanning electron microscopy (SEM) and optical microscopy were successfully generated with diameter distribution ranging from $3.8 \mu \mathrm{m}$ to $4.4 \mu \mathrm{m}$. The physical-chemical characterization including, FTIR, XRD, TG, and DTA, are explored and in vitro release profiles described by Ritger-Peppas models were also investigated, showing sustained release for $200 \mathrm{~h}$ after a burst release in the initial $12 \mathrm{~h}$. The drug-loaded microcapsules showed excellent anti-bacterial activities towards Escherichia coli (E. coli) and Staphylococcus aureus (S. aureus) by using both disk diffusion and minimal inhibitory concentration methods. The anti-oxidant performance was also evaluated by using DPPH assays. In vitro cell tests, including Cell Counting Kit-8, hemolysis experiments, and cell adhesion revealed that PLA-based microcapsules had significant biocompatibility and low cytotoxicity. The study showed that the PLAbased electrospray strategy combined with spherical microcapsules has the potential for a broad range of applications in medical fields, especially in drug delivery.
\end{abstract}

\section{Introduction}

Nowadays, more and more substances such as mesoporous inorganic materials, ${ }^{\mathbf{1 - 4}}$ microspheres, ${ }^{5-8}$ fibrous membranes, ${ }^{9-12}$ gelatin, ${ }^{13,14}$ and polymeric scaffolds ${ }^{15-19}$ have been extensively studied as carriers in drug delivery systems (DDSs) to encapsulate drugs and regulate release behavior, aiming to offer longterm durability and targeted therapy, as well as improving drug stability and bioavailability. ${ }^{\mathbf{2 0 - 2 2}}$ Accordingly, therapeutic efficacy could be not only influenced by the nature of drug itself, but also the methods and materials used to construct the DDSs. Among these, compared to the non-biodegradable polymers, biopolymer has attracted more attention due to their excellent biocompatibility and biodegradation, improved bioavailability

\footnotetext{
${ }^{a}$ Institute of Biomaterial, College of Materials and Energy, South China Agricultural University, Guangzhou, 510642, China.E-mail: zhouwuyi@scau.edu.cn

${ }^{b}$ Department of Anatomy, Guangdong Provincial Key Laboratory of Construction and Detection in Tissue Engineering, Southern Medical University, Guangzhou 510515, China.E-mail: huangwenhua2009@139.com

${ }^{c}$ Department of Materials Engineering, The University of British Columbia, Vancouver, BC, Canada V6T 1Z4. E-mail: frank.ko@ubc.ca

$\dagger$ Electronic supplementary information (ESI) available. See DOI: 10.1039/c6ra25314h

\$ Both authors contributed equally to this work.
}

of drugs. ${ }^{23,24}$ Moreover, the employment of biodegradable materials can immensely reduce the side effect and the risks of undesired toxicity inside the body. ${ }^{\mathbf{8}, 30}$ In recent years, polyethylene glycol (PEG), ${ }^{25}$ poly(lactic-co-glycolic) acid (PLGA), ${ }^{26}$ polycaprolactone (PCL), ${ }^{27}$ polyethylene oxide (PEO), ${ }^{28}$ polyvinyl alcohol (PVA) ${ }^{29}$ and chitosan (CS) ${ }^{30}$ have been widely employed in biomedical application owing to their excellent biodegradation properties inside the bodies. Specifically, polylactic acid (PLA) has been widely used as bioactive and biocompatible materials for different biomedical applications, such as drug delivery, ${ }^{31}$ wound dressing, ${ }^{32}$ artificial skin $^{33}$ and bone and tissue engineering. ${ }^{34} \mathrm{CO}_{2}$ and $\mathrm{H}_{2} \mathrm{O}$ are supposed to be the final products of PLA in vivo, which are nontoxic and friendly to human and environment. Additionally, PLA is more preferable due to its low-cost and availability from renewable sources. Furthermore, its properties such as molecular weight and degradation rates can be tuned to modify the controlled-release profiles of encapsuled drugs. ${ }^{31}$

In particular, PLA-based microcapsules have been largely investigated and proven to be one of the most efficient ways to encapsulate the therapeutic agents, providing high drug loading rate and sustain-release profiles. The conventional techniques of constructing microcapsules involve complex coacervation, ${ }^{5-7}$ solvent evaporation/extraction, ${ }^{35}$ spray drying, ${ }^{36}$ 
precipitation, ${ }^{37}$ in situ polymerization, ${ }^{38}$ etc. However, limitation of the above-mentioned methods was thoroughly investigated, demonstrating that all these techniques required complicate process and harsh conditions. Moreover, the key restriction is the difficulty to control the morphology and size distribution, which has been reported to be vital to tailor the drug release profiles and circulation inside the body. Monodispersity and appropriate shape of the microcapsules are more preferred since various uniformity and size distribution had different impact on the mechanisms of drug delivery in comprehensive ways. ${ }^{8,30,35}$

Electrospray (ES) has emerged to be one of the most costeffective and versatile technique to prepare polymeric fibrous membranes and micro/nanoparticles with diameters ranging from tens of nanometer to a few micrometer. ${ }^{8-12,29-31}$ The electrospray process depends on external high voltage electrical field and columbic repulsion, which induces the solvent of the charged droplets evaporate quickly, leaving micro/nano-sized solid directly reach the receptor. In the course of electrospraying, the solvent evaporates from the droplet and the drug remains entrapped within the polymer structure, ideally randomly distributed. The ES process have many unique advantages, i.e., high-effectiveness, rapidness and ease of operation..$^{29-31}$ Additionally, both morphology and particle size, which influences the cellular uptake and tissue uptake, can be facilely controlled by adjusting the operating parameters, i.e., flow rate, external voltage and polymer concentration, etc. Furthermore, either hydrophobic or hydrophilic drugs could be encapsuled into electrospray microcapsules with entrapment efficiency up to $100 \%$. As a result, electrospray micro/nano capsules were extensively investigated as novel drug vehicles owing to the above-mentioned advantages.

Curcumin (Cur), which was obtained from rhizomes of the Curcuma longa and used as food additives in lots of Asian countries, is becoming more and more popular for its diverse therapy properties and beneficial bioactivities. It has various biological applications such as antioxidant, anti-cancer, antimicrobial, antiphlogosis and antilipidemic effect. ${ }^{3,4}$ However, curcumin molecules were found to be unstable to a variety of physical and chemical environments, e.g., heat, $\mathrm{pH}$, light or alkali medium. Furthermore, its poor water solubility results in lower bioavailability, restricting its practical clinical trials. Therefore, in order to overcome these drawbacks, researchers have devoted to improve a series of drug delivery systems with enhanced remedial properties, including biocompatibility, hemocompatibility, cytotoxicity, cell adhesion and proliferation. ${ }^{25-27}$ A number of different techniques have been developed to construct such bioactive platforms. Compared to other manufacturing process, ES has been proven to be the most straightforward method to fabricate drug delivery systems.

In the present work, we firstly developed ES-based method to fabricate PLA microcapsules with uniform spherical shape and regular size distribution. Different operating parameters such as flow rate, chosen solvent, polymer/drug concentration were also investigated to further explore the mechanism of the fabrication process. Cur was chosen as the model drug molecular and successfully entrapped into the PLA-based microcapsules through mixing drugs with the polymer solution during electrospraying process. The obtained products were analyzed by Fourier Transform Infrared Spectroscopy (FTIR), X-Ray Diffraction (XRD), thermogravimetry (TG), and Differential Thermal Analysis (DTA). Morphology and size distribution were also explored by scanning electron microscope (SEM) and optical microscope (OM). The biocompatibility and cytotoxicity were further evaluated by cell proliferation and adhesion assays, as well as the hemolysis test (HT) and Cell Counting Kit-8 (CCK-8). The in vitro sustained release of Cur was also tested in $5 \mathrm{wt} \%$ SDS phosphate solution. Moreover, several bioactivities, i.e., antioxidant and antibacterial were also demonstrated by using 1,1-diphenyl-2-picrylhydrazyl (DPPH) assays and disk diffusion methods. Minimal inhibitory concentration method was also employed to quantitatively investigate the antibacterial ability. To the best of our knowledge, this is the first time to combine ES-based PLA microcapsules with Cur drugs, which gives an insight into how electrospray can provide a new method to fabricate polymeric novel drug carrying vehicles.

\section{Experimental methods}

\section{Materials}

PLA $\left(M_{\mathrm{w}}=80000-100000\right)$ was supplied by Jiejin Chemical Co., Ltd. (Guangdong, China). Curcumin (Cur) and 1,1-diphenyl-2picrylhydrazyl (DPPH) were purchased from Sigma-Aldrich. Acetone (AC), dichloromethane (DCM), tetrahydrofuran (THF) and trichloromethane (TCM) were provided by Sinopharm Chemical Reagent Co., Ltd. Human dermal fibroblast (HDF), Human embryonic kidney (HEK) 293T cells and rat pheochromocytoma PC12 cells were obtained from American Type Culture Collection (ATCC), USA. Fetal Bovine Serum (FBS) was supplied by GIBCO, Invitrogen, USA. 5 wt\% SDS (sodium dodecyl sulfate) solution was prepared as medium for drug release in vitro. All other materials and reagents used in this work were analytical graded unless otherwise noted.

\section{Experiment setup}

The schematic diagram of ES process is shown in Fig. 1. Spinning solutions were prepared in advance by dissolving different

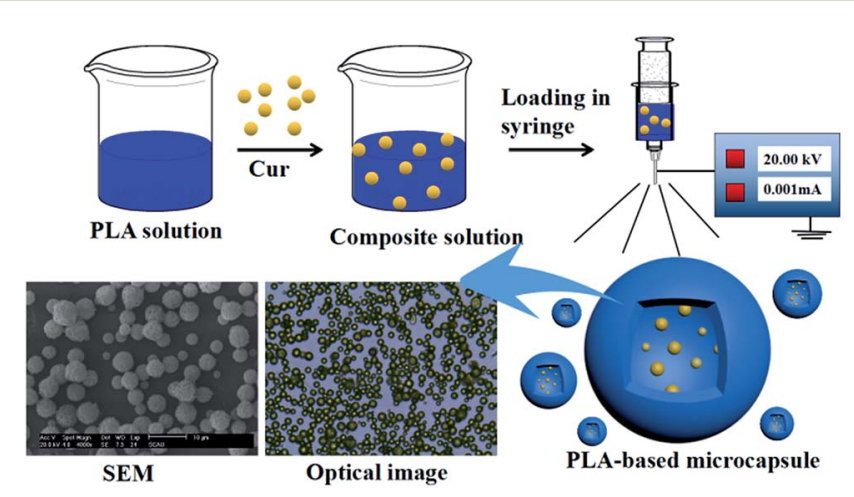

Fig. 1 Schematic description for fabrication of PLA-based microcapsules loaded with curcumin through electrospray process. 
Table 1 Summary of operating parameters setup for the ES fabrication process

\begin{tabular}{llll}
\hline Spinning solvent & $\begin{array}{l}\text { PLA } \\
\text { concentration }\end{array}$ & $\begin{array}{l}\text { Feeding } \\
\text { rate }\end{array}$ & $\begin{array}{l}\text { Drug } \\
\text { concentration }\end{array}$ \\
\hline Acetone & $1 \%$ & $0.1 \mathrm{~mL} \mathrm{~h}^{-1}$ & $0 \%$ \\
Dichloromethane & $3 \%$ & $0.3 \mathrm{~mL} \mathrm{~h}^{-1}$ & $5 \%$ \\
Tetrahydrofuran & $5 \%$ & $0.5 \mathrm{~mL} \mathrm{~h}^{-1}$ & $10 \%$ \\
Trichloromethane & $7 \%$ & $0.7 \mathrm{~mL} \mathrm{~h}^{-1}$ & $15 \%$
\end{tabular}

amount of PLA in various chosen solvent to achieve polymer mass fraction ranging from $1 \%$ to $7 \%$. Also, different amount of Cur (ranging from $0 \%$ to $15 \%$ ) was added to the polymeric solution. Each solution was kept under stirring overnight to form homogeneous system. All solutions were degassed and fed into $10 \mathrm{~mL}$ syringe, combined with a stainless steel capillary. The distance between the needle and grounded receptor was kept at $15 \mathrm{~cm}$ and applied voltage was maintained at $20 \mathrm{kV}$. The flow rates were kept at different values by a DT-200 precision syringe pump (Dalian Dingtong Technology Co., Ltd., China) to investigate the influence on morphology of the microcapsules. The obtained powders on grounded aluminum foil were collected and dried at $50{ }^{\circ} \mathrm{C}$ to remove the residual solvent. The powder was denoted as Cur@PLA (or CPLA) and details on different setup parameters were listed in Table 1. In particular, drug delivery systems with various drug concentrations $(0 \%$, $5 \%, 10 \%, 15 \%$ ) were denoted as $\mathrm{C}_{0}$ PLA, $\mathrm{C}_{5} \mathrm{PLA}, \mathrm{C}_{10} \mathrm{PLA}$ and $\mathrm{C}_{15}$ PLA, respectively.

\section{Characterization}

The morphology and shape of the obtained microcapsules under different operating parameters were observed via scanning electron microscope (SEM, Hitachi S-4800) and optical microscope (OM, Olympus CX23). The average particle sizes and distributions were determined by analyzing the SEM micrographs using the software nano-measurer $(n=200)$. Crystal structures of both PLA and Cur were determined by using XRD (D8 Advance, BRUKER). FTIR (Nicolet-Avatar 360) was used to evaluate the chemical structure and stability of drugs entrapped in carriers. The thermal degradation properties of different samples were examined using TG and DTA (DTG-60, SHIMADZU) under a Nitrogen flow rate of $20 \mathrm{~mL} \mathrm{~min}^{-1}$. The drug release behavior was studied by using UV-vis spectrophotometer (UV-2550, Shimadzu).

\section{Loading capacity of cur-loaded microcapsules}

The loading capacity (LC\%) and entrapment efficiency (EE\%) of Cur-loaded samples were measured by the following method. In brief, $5 \mathrm{mg}$ of sample was placed into $5 \mathrm{~mL}$ ethanol under sonication for $30 \mathrm{~min}$, in order to promote the drugs release thoroughly. After that, $45 \mathrm{~mL}$ PBS was mixed with Cur ethanol solution, which was then kept under vigorously shaking for $2 \mathrm{~h}$. The mixture was then centrifuged, and the supernatant was analyzed by UV-vis spectroscopy at the 425 wavenumber. The LC and EE were calculated by eqn (1) and (2).

$$
\begin{aligned}
& \mathrm{LC} \%=M_{t} / M_{\mathrm{s}} \times 100 \% \\
& \mathrm{EE} \%=M_{t} / M_{0} \times 100 \%
\end{aligned}
$$

where $M_{t}, M_{\mathrm{s}}$ and $M_{0}$ are the weight of Cur entrapped inside the microcapsules, the weight of drug delivery systems and the initial weight of Cur, respectively.

\section{In vitro release properties}

To measure the drug release behaviors of Cur@PLA microcapsules, $10 \mathrm{mg}$ of various samples were sealed in dialysis bags (8000-14 $000 \mathrm{Da}$, Sigma-Aldrich), which were further placed in $500 \mathrm{~mL}$ conical flasks filled $\mathrm{PBS}(0.2 \mathrm{M}, \mathrm{pH}=7.4)$ containing 0.5 $\mathrm{wt} \%$ SDS. The content was kept under gentle stirred in the dark at $37{ }^{\circ} \mathrm{C}$. At given intervals, $2 \mathrm{~mL}$ of drug release solution was withdrawn and then equivalent original PBS solution was added promptly, so as to keep the volume constant. The release solution was then measured by UV-vis spectrophotometer at the 425 wavenumber. The cumulative release percentage of Cur was calculated by using the following eqn (3).

$$
\begin{aligned}
& M_{t \text { corr }}=M_{t}+(v / V) \sum M_{t} \\
& \text { cumulative release rate } \%=M_{t \text { corr }} / M_{\text {total }} \times 100 \%
\end{aligned}
$$

where $M_{t}$ and $M_{t}$ corr are apparent weight and corrected weight at time t. $v$ is the volume of sample taken and $V$ is the total volume of release medium. $M_{\text {total }}$ is the total weight of Cur entrapped inside the microcapsules.

\section{Antioxidant activity test}

The antioxidant activity of Cur-loaded samples was estimated by using the DPPH assays. Briefly, various amounts of Cur-loaded samples were dispersed in ethanol to achieve different drug concentrations $\left(80 \mathrm{mg} \mathrm{mL} \mathrm{mL}^{-1}, 120 \mathrm{mg} \mathrm{mL}^{-1}, 160 \mathrm{mg} \mathrm{mL} \mathrm{mL}^{-1}\right.$, $200 \mathrm{mg} \mathrm{mL}^{-1}, 240 \mathrm{mg} \mathrm{mL}^{-1}$ ). After that, $5 \mathrm{~mL} 0.03 \mathrm{~g} \mathrm{~L}^{-1} \mathrm{DPPH}$ ethanol solution was mixed with $1 \mathrm{~mL}$ the obtained suspension. Subsequently, the reaction mixture was incubated in the dark at $25{ }^{\circ} \mathrm{C}$ for $30 \mathrm{~min}$. The purple $\mathrm{DPPH}$ solution faded and then absorbance at $517 \mathrm{~nm}$ of the supernatant was examined by UVvis spectroscopy. The antioxidant activity of each sample was assessed by using the eqn (4) below:

$$
\mathrm{DPPH}^{2} \%=\frac{A_{0}-A_{1}}{A_{0}} \times 100 \%
$$

where $A_{1}$ is the absorbance of DPPH solution mixture of $\mathrm{C}_{5} \mathrm{PLA}$, $\mathrm{C}_{10}$ PLA and $\mathrm{C}_{15}$ PLA and $A_{0}$ is the absorbance of control group using $\mathrm{C}_{0} \mathrm{PLA}$.

\section{Anti-bacterial assessment}

The anti-bacterial properties against Escherichia coli (E. coli) and Staphylococcus aureus ( $S$. aureus) were evaluated by a disk diffusion method. Briefly, E. coli and $S$. aureus were incubated by suspending bacterial in sterilized broth culture overnight at $37{ }^{\circ} \mathrm{C}$. Afterwards, the inoculation bacterial suspension was further diluted with sterilized water to $10^{5}$ (CFU) $\mathrm{mL}^{-1} .50 \mu \mathrm{L}$ of the diluted bacterial suspension was then spread throughout 
the nutrient agar plates. A filter paper was cut into disc with diameter of $6 \mathrm{~mm}$ and put on the surface of the agar plates. Next, $500 \mu \mathrm{L}$ of Cur@PLA suspension with concentration of $10 \mathrm{~g}$ $\mathrm{mL}^{-1}$ was placed on the filter paper, which was used as support to absorb the micro samples. After incubating at $37^{\circ} \mathrm{C}$ for $24 \mathrm{~h}$, the diameters of inhibition zones around the paper discs were measured. In order to further investigate the antibacterial activity quantitatively, minimal inhibitory concentration method was also applied. Briefly, Cur@PLA suspended in $5 \mathrm{~mL}$ PBS solution was incorporated with $5 \mathrm{~mL}$ nutrient broth to obtain a concentration of $20 \mathrm{mg} \mathrm{mL}{ }^{-1}$. Then, the suspension was treated with serial two-fold method and each gradient concentration was diluted to $10 \mathrm{mg} \mathrm{mL}^{-1}, 5 \mathrm{mg} \mathrm{mL}{ }^{-1}, 2.5 \mathrm{mg}$ $\mathrm{mL}^{-1}, 1.25 \mathrm{mg} \mathrm{mL}^{-1}, 0.625 \mathrm{mg} \mathrm{mL}^{-1}, 0.3125 \mathrm{mg} \mathrm{mL}^{-1}$ and $0.1563 \mathrm{mg} \mathrm{mL}^{-1}$, respectively. After regular culturing for $24 \mathrm{~h}$, $0.1 \mathrm{~mL}$ of the diluted suspension was plated on agar plates. Afterwards, the lowest concentration of capsules that showed visible antibacterial effect was defined as minimal inhibitory concentration (MIC). Specifically, suspension without drugloaded samples was used as control group.

\section{Cytotoxicity assay and hemolysis test}

In order to estimate the biocompatibility of the PLA-based microcapsules, both 293T cells and PC12 cells were incubated to assess the cytotoxicity through Cell Counting Kit-8 (CCK-8) and Hoechst 33342 strains experiments as observed by an upright fluorescence microscope (Olympus, BX50). Additionally, hemolytic test was also performed by using the blood drawn from SD rats to further assess the toxicity of the PLAbased samples. This research was conducted in accordance with the Declaration of Helsinki and with the Guide for Care and Use of Laboratory Animals as adopted and promulgated by the United National Institutes of Health. All experimental protocols were approved by the Review Committee for the Use of Human or Animal Subjects of Southern Medical University.

\section{Cell proliferation and adhesion assay}

The biocompatibility of $\mathrm{C}_{0}$ PLA and Cur@PLA was also assessed by using the human dermal fibroblast (HDF) as cell models. In brief, HDF cells were maintained firstly in DMEM, followed by adding $10 \%$ FBS and $1 \%$ anti-mycotic and anti-biotic at $37{ }^{\circ} \mathrm{C}$. The sterilized samples were immersed in the cell culture medium overnight to promote cell attachment. Typically, an empty culture plate was used as the control group. Afterwards, HDF cells was incubated with the samples at a density of $10^{4}$ cells per well. The number of HDF cells on different samples were counted using Beckman Vi-Cell XR Cell Viability Analyzer (Beckman Coulter, Inc., USA) after 1, 3 and 5 days. In addition, the morphology of HDF cells was also observed through SEM at specific times of cell culturing.

\section{Statistical analysis}

All data were expressed as mean standard deviation in this work. Statistical analysis was performed using $t$-test and statistical significance between mean values was regulated at $p<$ 0.10 .

\section{Results and discussion}

\section{Morphology of microcapsules fabricated under different spinning parameters}

Electrospray parameters, e.g., flow rate, polymeric concentration and solution composition were found to be most vital factors to be the most vital factors to influence the spinning products as previous discussed. ${ }^{8-12,29-31}$ The relation between the morphology of as-spun PLA-based products and abovementioned spinning parameters was firstly explored.

\section{Effect of spinning solvent}

The effect of organic solution used in ES process on the morphology of PLA-based microcapsules was firstly explored by selecting AC, DCM, THF and TCM as the spinning solvent. As is observed in Fig. 2, it is obvious that different solvents have significant impact on the morphology of the capsules. Apart from selecting TCM as solvent, other solvents were undesired because irregular and cracked spheres (Fig. 2a-c) were obtained when polymer concentration ranged from $1 \%$ to $7 \%$. Irregular spheres were obtained when using AC as solvent during ES process, which is mainly due to the poor dissolvability of PLA in such hydrophilic organics (Fig. 2a). Other undesired structures, i.e., cracked and sunken spheres, were also observed in Fig. $2 \mathrm{~b}$ and $\mathrm{c}$, which can be attributed to the volatility of DCM and THF. In particular, uniform and spherical PLA capsules can be obtained by selecting TCM as solvent, which resulted from its proper volatility and excellent solubility to PLA.

\section{Effect of flow rate}

Fig. 3 reveals the influence of flow rate on the morphology of PLA capsules during ES process. According to the abovementioned research, TCM was chosen as the solvent to form the spinning solution. In order to investigate the influence of flow rate more precisely, we collected the samples by placing a glass slide on the grounded receptor as soon as steady polymer

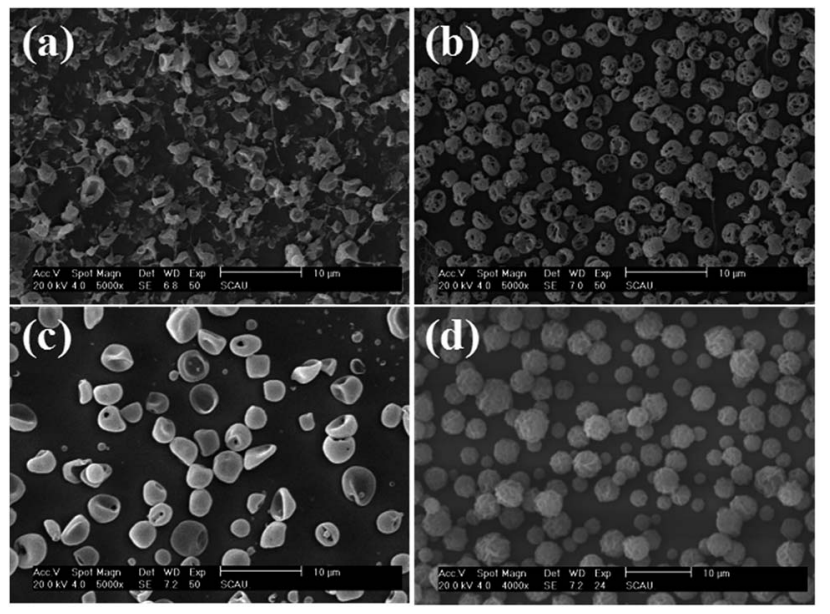

Fig. 2 SEM images of PLA microcapsules using different spinning solvent ((a) acetone, (b) dichloromethane, (c) tetrahydrofuran, (d) trichloromethane). 

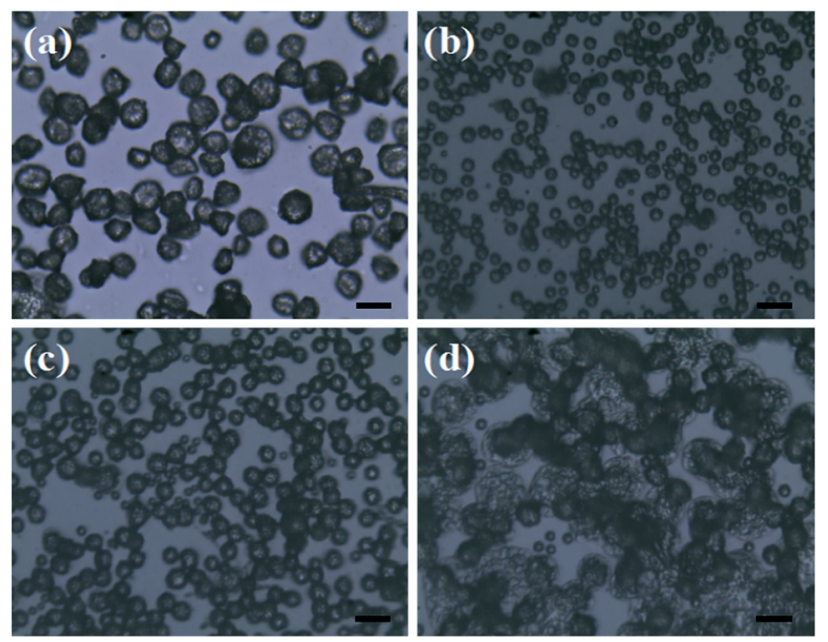

Fig. 3 Optical images of PLA microcapsules under different flow rate ((a) $0.1 \mathrm{~mL} \mathrm{~h}^{-1}$, (b) $0.3 \mathrm{~mL} \mathrm{~h}^{-1}$, (c) $0.5 \mathrm{~mL} \mathrm{~h}^{-1}$, (d) $0.7 \mathrm{~mL} \mathrm{~h}^{-1}$ ) scale bar $=$ $20 \mu \mathrm{m}$.

flow was generated. As can be seen in optical micrographs shown in Fig. $3 \mathrm{~b}, 0.3 \mathrm{~mL} \mathrm{~h}^{-1}$ can be the optimal flow rate to fabricate uniform and monodisperse PLA spheres. By contrast, at flow rates of either higher or lower than $0.3 \mathrm{~mL} \mathrm{~h}^{-1}$ it would be difficult to control the monodispersity and structure, as well as the size distribution (Fig. 3a, c and d).

It is chiefly caused by adjusting the evaporating rate of TCM during the ES process when exposed to different flow rates.

\section{Effect of PLA concentration}

Polymer concentration is a recognized important factor in controlling the morphology of as-spun products. As shown in Fig. 4, polymer structures varied from monodispersed spheres
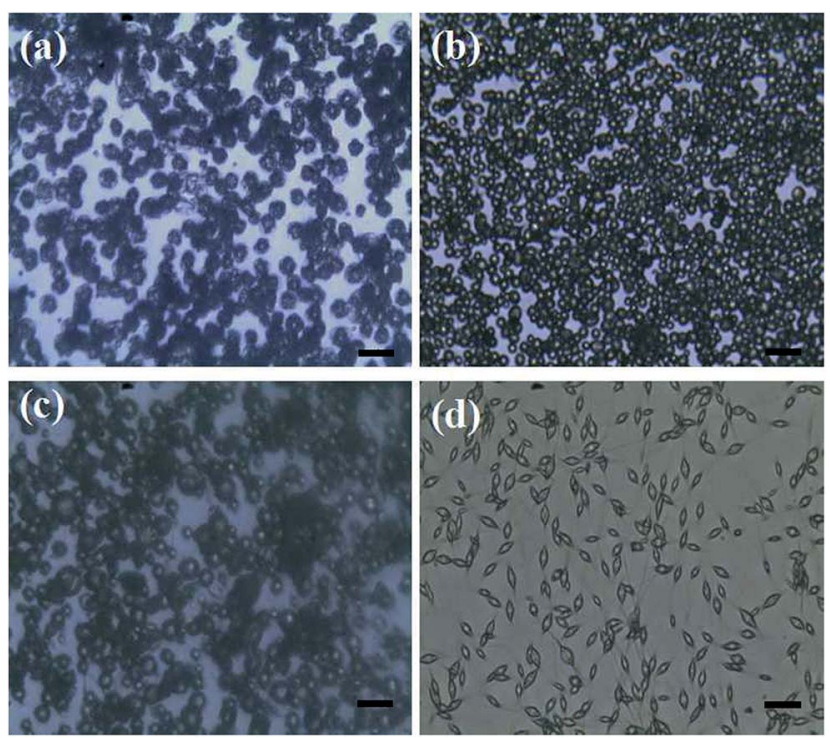

Fig. 4 Optical images of PLA microcapsules using different PLA concentration ((a) $1 \%$, (b) $3 \%$, (c) $5 \%$, (d) $7 \%$ ). Scale bar $=20 \mu \mathrm{m}$. to beaded fibers, which was supposed to be relevant to the polymer concentration used in ES process. In other words, when polymer concentration is low ( $1 \mathrm{wt} \%)$, microspheres are more likely to be non-uniform (Fig. 4a). When polymer concentration reaches 5\%, agglomerated spherical hollow particles are produced (Fig. 4c). Furthermore, as the polymer concentration became higher (Fig. 4, $7 \mathrm{wt} \%$ ), beaded nanofibers tend to be generated, which can be due to the effect of electrical conductivity and the surface tension of the spinning solutions with different polymer concentrations..$^{29-31}$ Thus, too high a polymer concentration resulted in the formation of agglomeration. In general, as shown in Fig. 4a, PLA concentration of $3 \mathrm{wt} \%$ is most suitable to produce uniform and micro spheres with smooth surface and less defect structures.

\section{Effect of drug concentration}

At a given flow rate $\left(0.3 \mathrm{~mL} \mathrm{~h}^{-1}\right)$ and polymer concentration (3 wt\%), Fig. 5 displays the Cur@PLA microcapsules with different drug contents of $0 \%, 5 \%, 10 \%$ and 15 wt $\%$ with all other spinning parameters fixed, along with the particle size distribution graphs. As seen from the SEM images, the particle distribution is slightly influenced after adding different amounts of drug molecular to the spinning solution. The mean particle diameters for $\mathrm{C}_{0} \mathrm{PLA}, \mathrm{C}_{5} \mathrm{PLA}, \mathrm{C}_{10} \mathrm{PLA}, \mathrm{C}_{15}$ PLA were $3.8 \pm$ $0.3 \mu \mathrm{m}, 4.0 \pm 0.7 \mu \mathrm{m}, 4.2 \pm 0.6 \mu \mathrm{m}$ and $4.4 \pm 0.8 \mu \mathrm{m}$, respectively. The slight increase of spherical size is evident of the successful loading of drug molecules, which could be further interpreted as reduction of the conductivity with adding more Cur drugs into the spinning solution, resulting in increases of the diameters of PLA microparticles. In other words, there was no obvious drug crystals observed on the surface of the microparticles, revealing the consummate drug entrapment process. Moreover, Fig. 6 shows the optical images of $\mathrm{C}_{0} \mathrm{PLA}, \mathrm{C}_{5} \mathrm{PLA}$, $\mathrm{C}_{10}$ PLA and $\mathrm{C}_{15}$ PLA. It is clearly observed that the yellow Cur molecular was encapsulated inside the core of the PLA-based
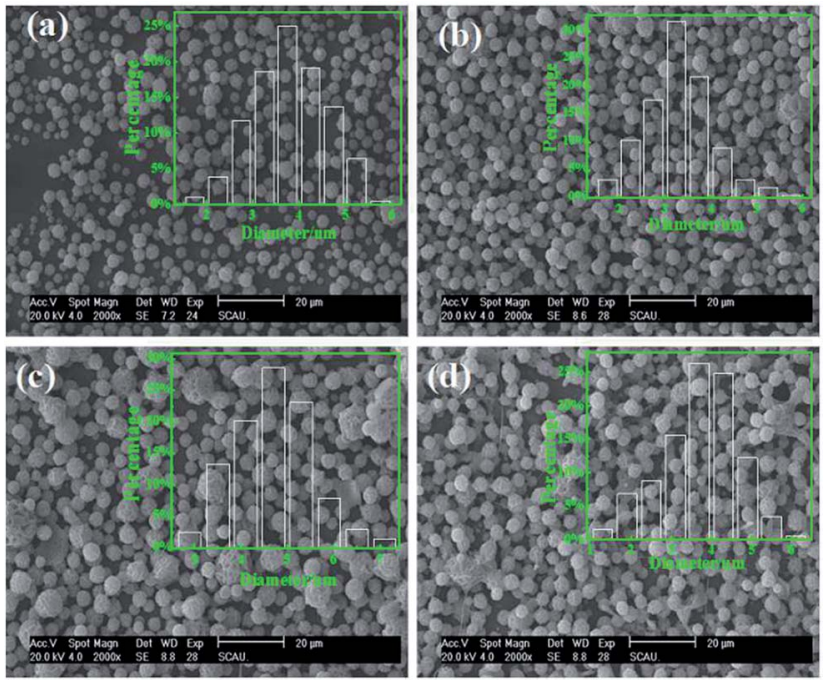

Fig. 5 SEM images of PLA microcapsules using different drug concentration ((a) $0 \%$, (b) $5 \%$, (c) $10 \%$, (d) $15 \%$ ). 

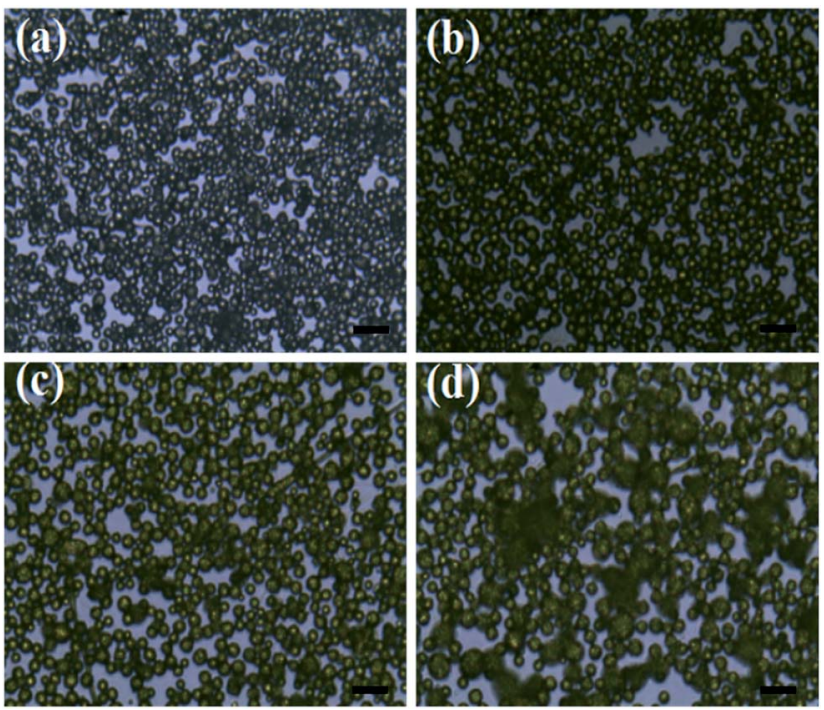

Fig. 6 Optical images of PLA microcapsules using different drug concentration ((a) $0 \%$, (b) $5 \%$, (c) $10 \%$, (d) $15 \%$ ) scale bar $=20 \mu \mathrm{m}$.

carrier vehicles. In addition, bright green fluorescent signals were observed through fluorescence microscope (Fig. S2 $\dagger$ ), which further indicated the presence of Cur in the core of the microcapsules. Meanwhile, the LC (\%) and EE (\%) for different samples produced through the ES process are listed in Fig. S3. $\dagger$ As can be seen, the drug entrapment efficiencies of the microcapsules at optimal parameters (i.e. flow rate $=0.3 \mathrm{~mL} \mathrm{~h}^{-1}$, PLA concentration $=3 \%$ and TCM as the solvent) are found to be in the range of $95-97 \%$, which can be considered to be no drug loss during the fabrication process. This shows the unique advantage of the ES process compared to the conventional methods. ${ }^{35-38}$ Taking into consideration of toxic side effect and bioavailability of the targeted drugs, $\mathrm{C}_{10}$ PLA is chosen as the best candidate and $10 \%$ of drug content was supposed to be reasonable in this work.

\section{FTIR}

The results of FTIR analysis of $\mathrm{C}_{0}$ PLA, $\mathrm{C}_{10}$ PLA, pure Cur and physical mixture of Cur and $\mathrm{C}_{0}$ PLA (mass ratio of Cur to $\mathrm{C}_{0}$ PLA: 1/10) are shown in Fig. 7a. In order to verify the successful fabrication procedure, different peaks of each sample were examined. As for $\mathrm{C}_{0}$ PLA, peaks at $1766 \mathrm{~cm}^{-1}$ and $1092 \mathrm{~cm}^{-1}$ can be attributed to the stretching vibration of $\mathrm{C}=\mathrm{O}$ bonds and $\mathrm{C}-\mathrm{O}$ bonds, respectively. In addition, asymmetrical vibrations of $-\mathrm{CH}_{3}$ bonds at $1455 \mathrm{~cm}^{-1}$ and $1390 \mathrm{~cm}^{-1}$ are also observed. Similarly, $\mathrm{C}_{10}$ PLA kept the characteristic peaks at featured wave numbers, which indicated that the polymer remained stable during ES process. The spectrum of pure Cur exhibited the characteristic peaks at $1618 \mathrm{~cm}^{-1}, 1516 \mathrm{~cm}^{-1}, 1270 \mathrm{~cm}^{-1}$ and $879 \mathrm{~cm}^{-1}$, which can be ascribed to the stretching vibration of $\mathrm{C}=\mathrm{O}$ bonds, $\mathrm{C}=\mathrm{C}$ bonds, $\mathrm{C}-\mathrm{O}$ bonds and $\mathrm{C}-\mathrm{O}-\mathrm{C}$ bonds, respectively. Based on the FTIR analysis, no additional peaks were found, which was the same as the FTIR spectra of physical mixture of drug and polymer, proving that no chemical reaction occurred among the raw materials during the ES process. The
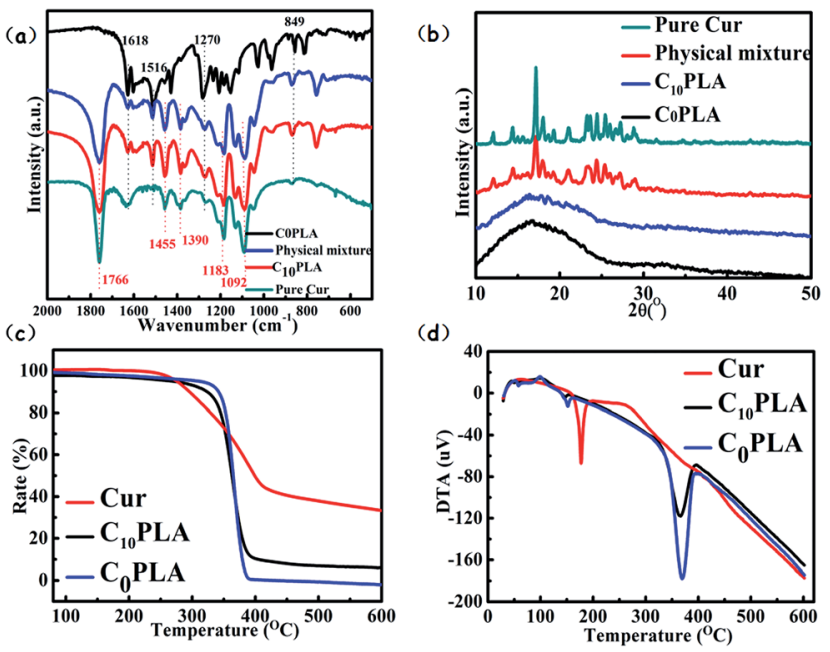

Fig. 7 (a) FTIR (b) XRD (c) TGA (d) DTA curves of Cur, $\mathrm{C}_{10}$ PLA and $\mathrm{C}_{0} \mathrm{PLA}$, respectively.

main peaks of Cur were also seen in $\mathrm{C}_{10} \mathrm{PLA}$, which could be concluded as the successful immobilization of cargoes inside the PLA-based vehicles. ${ }^{3,4}$

\section{XRD}

$\mathrm{X}$-ray diffraction experiments were performed to assess the crystallinity of each samples, i.e., $\mathrm{C}_{0}$ PLA, pure Cur and $\mathrm{C}_{10}$ PLA. To investigate the crystalline nature during the ES process thoroughly, physical mixture of Cur and $\mathrm{C}_{0}$ PLA (mass ratio of Cur to $\mathrm{C}_{0}$ PLA: $1 / 10$ ) was also tested. All the XRD results were displayed in Fig. 7b. Typically, $\mathrm{C}_{0} \mathrm{PLA}$ did not show obvious peaks in the wide-angle range from $10^{\circ}$ to $50^{\circ}$ corresponding to any crystal phase, implying the amorphous nature of PLA microcapsules fabricated by ES techniques. Besides, it was seen that pure Cur showed main peaks at $2 \theta=17.5^{\circ}$, and other characteristic diffraction peaks ranging from $20^{\circ}$ to $30^{\circ}$ were also detected with strong intensity, indicating that pure Cur drugs existed in crystalline form. Similar peaks corresponding to the Cur crystal phase are also observed in the XRD pattern of the physical mixture. However, $\mathrm{C}_{10}$ PLA showed no diffraction peaks, illuminating the transform of Cur crystals to amorphous phase during the ES process. This could probably be caused by the fact that most drug molecules were trapped into the core of the microcapsules, which is consistent with the SEM observation mentioned above.

\section{Thermal properties}

The thermal features of $\mathrm{C}_{0}$ PLA and $\mathrm{C}_{10}$ PLA were analyzed based on TG and DTA curves. As observed in Fig. 7c, Cur began to lose weight at about $250{ }^{\circ} \mathrm{C}$ due to the thermal decomposition, gradually resulting in $40 \%$ of its weigh under $600{ }^{\circ} \mathrm{C}$ in $\mathrm{N}_{2}$ atmosphere. Apart from pure Cur, both $\mathrm{C}_{0} \mathrm{PLA}$ and $\mathrm{C}_{10} \mathrm{PLA}$ underwent similar decomposition path except for the starting temperature of losing weight. Typically, both of them started losing weight at about $350{ }^{\circ} \mathrm{C}$, which was supposed to be higher than that of pure Cur. It was notable that the gap of weight-loss 
rates between them was estimated to stay at $9.96 \%$, which can be considered as the loading capacity of Cur (10\% theoretically), as well as another evidence to prove the high entrapment efficiency of ES fabrication. The DTA curves gave detailed description of the decomposition occurred during the temperature-rise period as shown in Fig. 7d. As described above, endothermic peaks were observed for pure Cur at $200{ }^{\circ} \mathrm{C}$ due to the organic decomposition under $\mathrm{N}_{2}$. However, endothermic peaks for $\mathrm{C}_{0}$ PLA and $\mathrm{C}_{10}$ PLA were found at $350{ }^{\circ} \mathrm{C}$, which was consistent with the TG analysis. In particular, no weigh loss for $\mathrm{C}_{10}$ PLA below $200{ }^{\circ} \mathrm{C}$ were observed, which can be concluded as the improved thermostability of drugs provided by the outer shell materials.

\section{In vitro release}

The in vitro drug release properties of various Cur-loaded samples were analyzed by using PBS $(0.2 \mathrm{M}, \mathrm{pH}=7.4)$ containing $0.5 \mathrm{wt} \%$ SDS. Fig. 8 show the release profiles of microcapsules with different drug loading capacities. It can be seen that all of them exhibited similar Cur sustained release behaviors during the whole period, including an initial burst release phase and an apparently slow release stage. In detail, the cumulative release rates of the microcapsules reached $51.23 \pm$ $2.3 \%, 58.5 \pm 3.5 \%$ and $67.6 \pm 2.2 \%$ after $24 \mathrm{~h}$ for $\mathrm{C}_{5} \mathrm{PLA}, \mathrm{C}_{10} \mathrm{PLA}$ and $\mathrm{C}_{15} \mathrm{PLA}$, respectively. All of them displayed initial burst effect during the first $24 \mathrm{~h}$, followed by a sustained release for $200 \mathrm{~h}$. This phenomenon in the first stages can be attributed to fast release of Cur absorbed on the outer surface or near the interior of the microcapsules. ${ }^{3,5}$ These external drugs dissolved in SDS solution quickly at the early stage of the release process. Subsequently, the cumulative rates of Cur became gradually steady as time passing. It can be explained by the fact that Cur molecules dissolved and migrated to the surroundings through permeation and effusion from the voids of microcapsules. In other words, diffusion path of Cur was increased and differential concentration was decreased between the nanosystems and surrdoundings. ${ }^{5,6}$ Meanwhile, the cumulative release amounts

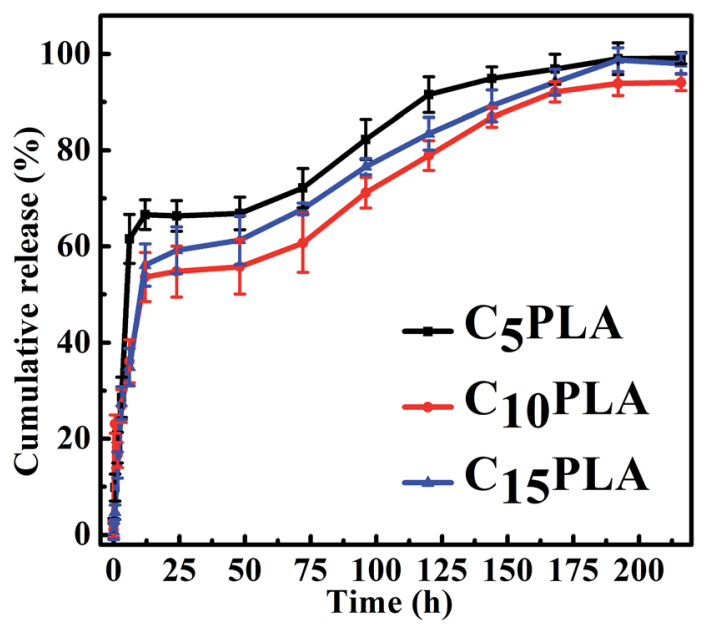

Fig. 8 Drug release profiles of $\mathrm{C}_{5} \mathrm{PLA}, \mathrm{C}_{10} \mathrm{PLA}$ and $\mathrm{C}_{15} \mathrm{PLA}$ in 5\% SDS phosphate solution ( $\mathrm{pH}=7.4$ ). of Cur increased slowly after $24 \mathrm{~h}$ and the drug release would be fostered by the gradual degradation of PLA at this stage. Finally, it can be seen that after $200 \mathrm{~h}$, the cumulative release amounts of $\mathrm{C}_{5} \mathrm{PLA}, \mathrm{C}_{10} \mathrm{PLA}$ and $\mathrm{C}_{15} \mathrm{PLA}$ are $94.22 \pm 1.1 \%, 95.37 \pm 1.5 \%$ and $96.77 \pm 1.2 \%$, respectively. This suggests that by using ES method, high loading capacity and long-acting drug delivery nanosystems can be prepared.

In order to further investigate the drug release mechanism of Cur from the PLA-based microcapsules fabricated by ES process, four pharmacokinetic models (zero-order, first-order, Higuchi and Ritger-Peppas) were explored to fit to the drug release profiles.

Zero-order model:

$$
Q=K t
$$

First order model:

$$
Q=1-\exp (-K t)
$$

Higuchi model:

$$
Q=K t^{1 / 2}
$$

Ritger-Peppas model:

$$
Q=K t^{n}
$$

where $K, Q, n$ and $t$ are the kinetics constant, cumulative release ratio, diffusion exponent and release time, respectively. Accordingly, the diffusion exponent $(n)$ is used to indicate various release mechanism, or to examine whether the release mechanisms followed the Fickian diffusion or not. ${ }^{9}$

From the fitted results, as shown in Table 2, zero-order model does not suitably describe the release mechanism of the microcapsules, with correlation coefficient $\left(R^{2}\right)$ of 0.81368 , 0.84413 and 0.74724 for $\mathrm{C}_{5} \mathrm{PLA}, \mathrm{C}_{10} \mathrm{PLA}$ and $\mathrm{C}_{15} \mathrm{PLA}$, respectively. However, the release results showed preference towards Ritger-Peppas model with a correction coefficient $R^{2}$ higher than 0.95 for each sample, compared to the fist-order model $\left(R^{2}\right.$ $=0.90-0.92)$ and Higuchi model $\left(R^{2}=0.91-0.93\right)$. In addition, diffusion exponent $(n)$ was found to be in the range from 0.43 to 0.85 , which indicate that release of Cur-loaded microcapsules followed a non Fickian diffusion. ${ }^{5}$ This also reveals the fact that the Cur release from the microcapsules is controlled by both diffusion and matrix degradation, when the diffusion exponent was larger than $0.45 .^{6}$ The degradation is probably a result of the hydrolysis of PLA on the surface. ${ }^{9}$

\section{Antioxidant tests}

The antioxidant properties of the Cur-loaded capsules were tested using the DPPH radicals, which was recognized as typical free radicals and widely used to evaluate the antioxidative effect due to its sensitivity to free-radical scavenger. ${ }^{39,40}$ Accordingly, a range of gradient concentrations of samples $\left(80 \mathrm{mg} \mathrm{mL}^{-1}\right.$, $120 \mathrm{mg} \mathrm{mL}^{-1}, 160 \mathrm{mg} \mathrm{mL}^{-1}, 200 \mathrm{mg} \mathrm{mL}^{-1}, 240 \mathrm{mg} \mathrm{mL}^{-1}$ ) were incubated with DPPH solution. After reaction for $30 \mathrm{~min}$, the purple solution faded due to the clearance of DPPH radicals and 
Table 2 Fitting parameters of Cur release behaviors to different kinetic models

\begin{tabular}{lllll}
\hline Sample & Zero-order model & First order model & Higuchi model & Ritger-Peppas model \\
\hline $\mathrm{C}_{5}$ PLA & $Q=0.27877+0.00495 t, R^{2}=$ & $\ln (1-Q)=-0.25790-$ & $Q=0.20088+0.06592 t^{1 / 2}, R^{2}$ & $\ln Q=-2.13143+$ \\
& 0.81368 & $0.01422 t, R^{2}=0.92129$ & $=0.93591$ & $0.53694 \ln t, R^{2}=0.94307$ \\
$\mathrm{C}_{10}$ PLA & $Q=0.32571+0.00455 t, R^{2}=$ & $\ln (1-Q)=-0.31940-$ & $Q=0.20291+0.06094 t^{1 / 2}, R^{2}$ & $\ln Q=-1.67791+$ \\
& 0.84413 & $0.01318 t, R^{2}=0.93313$ & $=0.94817$ & $0.44071 \ln t, R^{2}=0.95361$ \\
$\mathrm{C}_{15}$ PLA & $Q=0.34484+0.00483 t, R^{2}=$ & $\ln (1-Q)=-0.34072-$ & $Q=0.13812+0.06462 t^{1 / 2}, R^{2}$ & $\ln Q=-1.74589+$ \\
& 0.74724 & $0.01706 t, R^{2}=0.90436$ & $=0.92339$ & $0.48167 \ln t, R^{2}=0.93726$
\end{tabular}

(a)

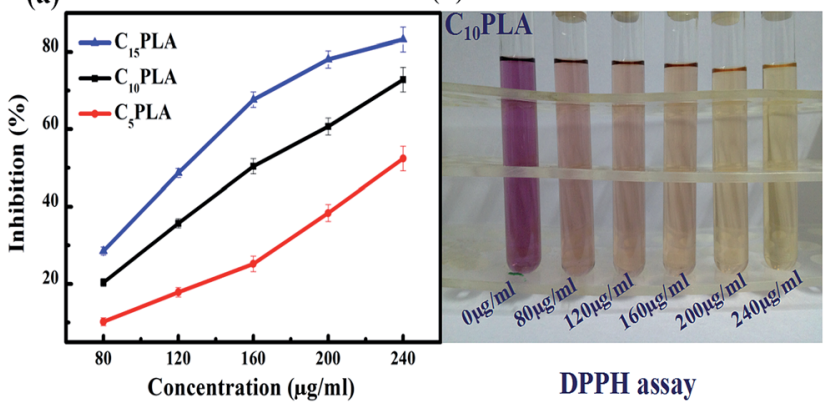

Fig. 9 (a) Antioxidant test results of $C_{5}$ PLA, $C_{10}$ PLA and $C_{15}$ PLA towards DPPH free radicals. (b) DPPH series towards the sample of $\mathrm{C}_{10}$ PLA.

the inhibition rates were calculated by using the UV-vis spectroscopy. As shown in Fig. 9, the half maximal inhibitory concentrations $\left(\mathrm{IC}_{50}\right)$ of $\mathrm{C}_{5} \mathrm{PLA}, \mathrm{C}_{10}$ PLA and $\mathrm{C}_{15}$ PLA were 236.66 $\mu \mathrm{g} \mathrm{mL} L^{-1}, 163.11 \mu \mathrm{g} \mathrm{mL}^{-1}$ and $122.26 \mu \mathrm{g} \mathrm{mL}^{-1}$, respectively. This result may be associated with the content inside the microcapsules and notably Cur remained bioactive after ES fabrication, which is an important consideration when producing novel drug delivery systems.

\section{Antibacterial tests}

The antibacterial effects of $\mathrm{C}_{10} \mathrm{PLA}$ suspension towards $E$. coli and $S$. aureus were assessed by using disc diffusion method, combined with plate counting method. The $\mathrm{C}_{0}$ PLA suspension showed no inhibition zone, declaring that pure PLA does not possess any antibacterial properties. In comparison, Fig. 10c and $\mathrm{d}$ revealed the inhibition zone of $\mathrm{C}_{10}$ PLA against $E$. coli and $S$. aureus, and the diameters of inhibition zones were measured at $2.90 \pm 0.04 \mathrm{~cm}$ and $3.24 \pm 0.04 \mathrm{~cm}$, indicating the distinct antibacterial effect of $\mathrm{C}_{10}$ PLA on $E$. coli and $S$. aureus. Furthermore, in order to investigate the antibiotic ability of $\mathrm{C}_{10} \mathrm{PLA}$ quantitatively, plate-counting method was also applied. As seen in Table 3, the MICs for $\mathrm{C}_{10} \mathrm{PLA}$ against $E$. coli and $S$. aureus were found to be $1.25 \mathrm{mg} \mathrm{mL}^{-1}$ and $0.625 \mathrm{mg} \mathrm{mL}^{-1}$, revealing the high-efficient antibacterial activity of microcapsules fabricated through ES process even at such low concentration.

\section{In vitro cell test}

The drug delivery material, $\mathrm{C}_{0} \mathrm{PLA}$, was tested for hemolysis experiments and cell apoptosis with Hoechst 33342 staining

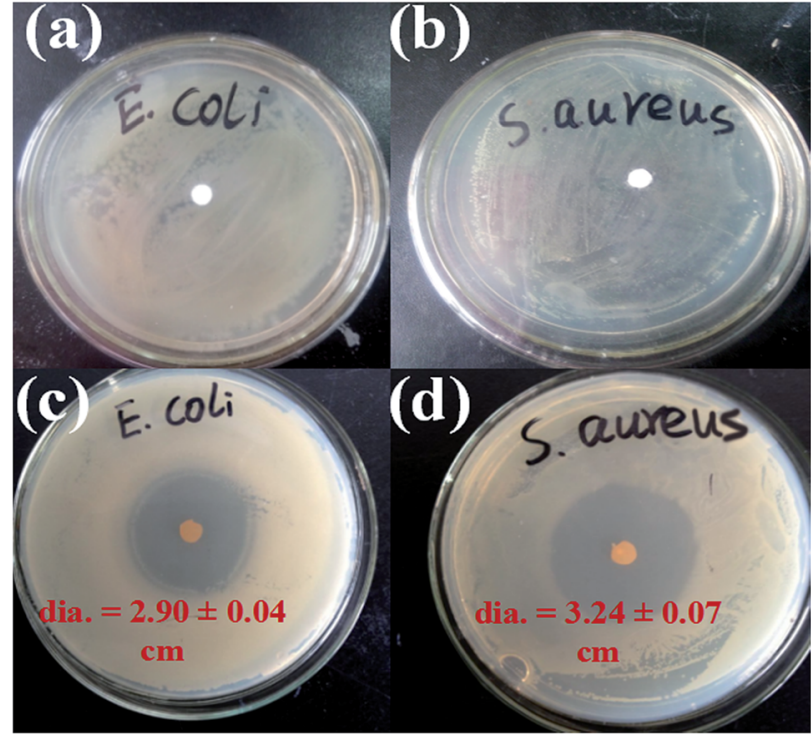

Fig. 10 Bactericidal activity of $C_{0} P L A$ towards (a) E. coli and (b) S. aureus and antibacterial activities of $\mathrm{C}_{10}$ PLA showing inhibition zones towards (c) E. coli and (d) S. aureus.

experiment to determine the cytotoxicity and biocompatibility. In addition, cell adhesion and proliferation assays with HDF were also conducted to evaluate the cytocompatibility after culturing for 5 days.

\section{Hemolytic assay assessment}

To evaluate the biocompatibility of PLA-based microcapsules, a wide range of concentrations of $\mathrm{C}_{0}$ PLA (15.625-500 $\mu \mathrm{g}$ $\mathrm{mL}^{-1}$ ) in PBS suspension were incubated with blood samples from SD rats. As shown in Fig. 11a, the hemolytic rate results revealed no significant hemolysis of red blood cells (RBCs) with concentrations of samples reaching up to $500 \mu \mathrm{g} \mathrm{mL} \mathrm{m}^{-1}$. Typically, only almost $13 \%$ hemolytic activity was detected even at a high concentration of $500 \mu \mathrm{g} \mathrm{mL} \mathrm{m}^{-1}$, indicating that the PLA capsule possessed good biocompatibility and low cytotoxicity.

\section{Cell viabilities assessment}

We used cell counting kit-8 (CCK-8) to further assess the cytotoxicity of PLA-based microcapsule with HEK 293T cells (2500 cells per well) or PC12 cells (2500 cells per well) incubated with different concentration of samples for $48 \mathrm{~h}$, as 
Table 3 Minimal inhibitory concentration towards $E$. Coli and S. aureus for $C_{10} P L A$ (" -" there is no growth for bacteria, " + " there is growth for bacteria)

\begin{tabular}{|c|c|c|c|c|c|c|c|c|c|}
\hline Sample $\left(\mathrm{mg} \mathrm{mL}^{-1}\right)$ & Bacteria & 20 & 10 & 5 & 2.5 & 1.25 & 0.625 & 0.312 & 0.156 \\
\hline \multirow[t]{2}{*}{$\mathrm{C}_{10}$ PLA } & E. coli & - & - & - & - & - & - & - & + \\
\hline & S. aureus & - & - & - & - & - & - & - & + \\
\hline
\end{tabular}

(a)

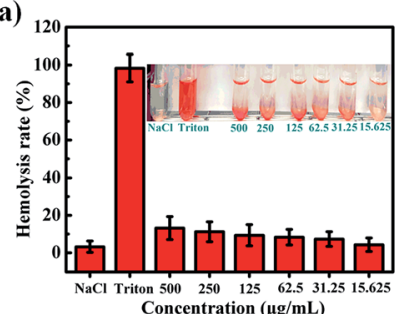

(b)

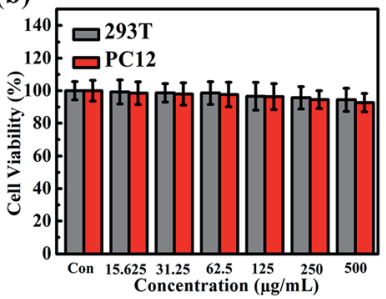

Fig. 11 Hemolysis assays for (a) $C_{0}$ PLA at concentrations from 15.625 $\mu \mathrm{g} \mathrm{mL} \mathrm{m}^{-1}$ to $500 \mu \mathrm{g} \mathrm{mL}{ }^{-1}$, (b) cell viabilities assessments of PLA microcapsules (or $\mathrm{C}_{0} \mathrm{PLA}$ )

shown in Fig. 11b. It is obvious that $\mathrm{C}_{0} \mathrm{PLA}$ showed no significant effect on the cell viability for both HEK 293T cells and PC12 cells, implying the low cytotoxicity of the microcapsules. Specifically, it was noted that the cell viability was measured as over $80 \%$ even at a high concentration of $500 \mu \mathrm{g}$ $\mathrm{mL}^{-1}$. The immunofluorescence microscopy experiment of cell apoptosis in 293T cells and PC12 cells is also displayed in Fig. S4. $\dagger$ As can be seen, few deformed cell nuclei was detected, indicating that the microcapsules do not cause apoptosis at high concentration. ${ }^{\mathbf{4 1 , 4 2}}$

\section{Cell adhesion and proliferation}

In order to further investigate the biocompatibility of PLAbased microcapsules, the morphology of HDF cells incubated with different samples were also explored in depth. The SEM graphs of proliferated HDF cells on $\mathrm{C}_{0}$ PLA and $\mathrm{C}_{10} \mathrm{PLA}$ at different times were displayed in Fig. 12a-f. As can be seen, the cells tended to grow and adhere to the gaps among microcapsules on the first day, thin cellular layers were obviously observed after proliferation for 3 days, indicating the excellent biocompatibility of both PLA-based samples. In particular, it is worth noting that cell morphology for $\mathrm{C}_{0}$ PLA and $\mathrm{C}_{10}$ PLA shows no difference on the fifth day, which meant that drug molecules had no negative effect on the cell adhesion and proliferation.

Fig. $12 \mathrm{~g}$ indicated the numbers of HDF cells on different samples at given times. Notably, HDF cells grew more rapidly on the $\mathrm{C}_{0}$ PLA microcapsules and $\mathrm{C}_{10}$ PLA microcapsules than the control group, which can be simply attributed to the better biocompatibility of PLA. In particular, higher surface area provided by the micro-sized capsules was probably another important factor leading to the rapid cell adhesion and proliferation. Consistently, there was no significant difference between $\mathrm{C}_{0} \mathrm{PLA}$ and $\mathrm{C}_{10}$ PLA on cell
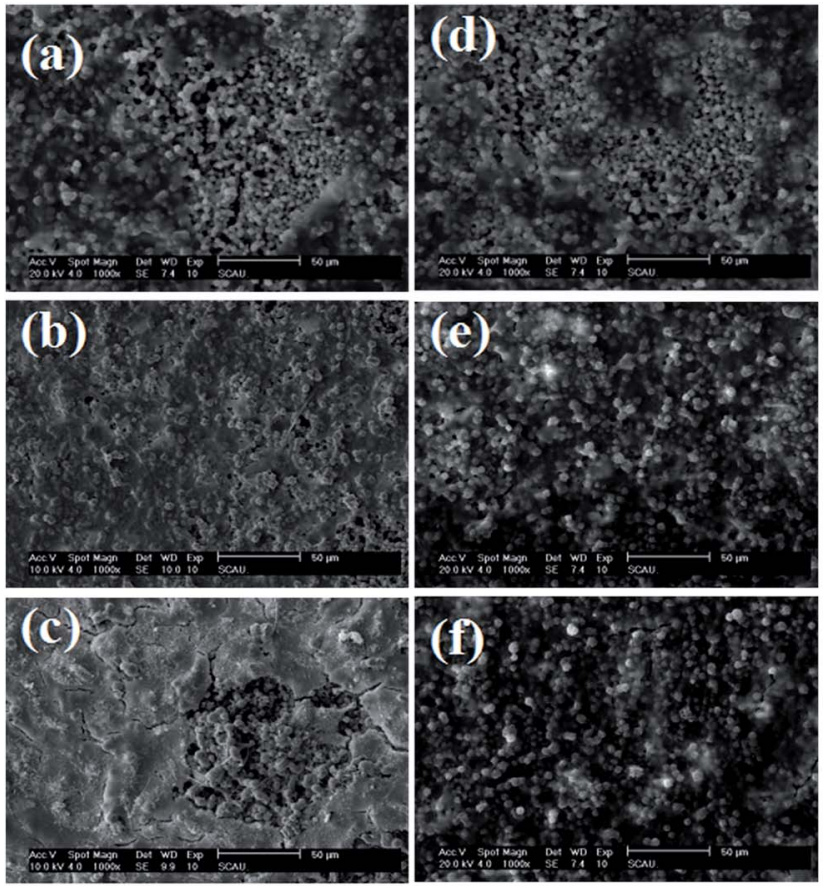

(g)

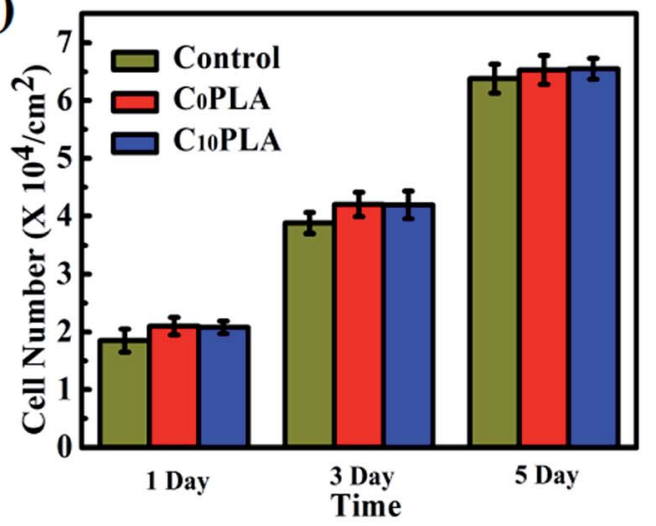

Fig. 12 (a)-(f) SEM images of cells growth on the surface of $C_{0} P L A$ and $\mathrm{C}_{10} \mathrm{PLA}$ for 1, 3, 5, 7 days, respectively; (g) proliferation of the HDF cells cultured on $\mathrm{C}_{0} \mathrm{PLA}$ and $\mathrm{C}_{10} \mathrm{PLA}$ and control group.

number, indicating that both of them possessed outstanding biocompatibility. ${ }^{43}$

\section{Conclusions}

In summary, we successfully fabricated novel PLA-based microcapsules entrapped with Cur drugs through an electrospray process. The morphology and particle sizes could be 
optimized by adjusting spinning solvent, flow rates, polymer and drug concentrations. Cur could be encapsulated inside the PLA microcapsules with entrapment efficiency higher than $95 \%$. A sustained release of Cur from the microcapsules can be reached for up to $200 \mathrm{~h}$. Moreover, several bioactivities such as anti-microbial and antioxygenation were confirmed to be outstanding. Meanwhile, with low cytotoxicity and brilliant biocompatibility evaluated by CCK-8, hemolysis and cell adhesion tests, we believed that these novel electrospun PLA-based drug delivery systems have further potential in clinical medicine.

\section{Acknowledgements}

The work was supported by the Science and Technology Foundation of Guangdong Province (2016A050502044, 2015B020237009), Natural Science Foundation of Guangdong Province in China (2014A030310035; 2016A030313602), and Aid Program for Science and Technology Innovative Research Team in Higher Educational Institutions of Hunan Province.

\section{Notes and references}

1 X. J. Wang, D. H. Chen, L. Cao, Y. C. Li, B. J. Boyd and R. A. Caruso, ACS Appl. Mater. Interfaces, 2013, 5, 1092610932.

2 F. Liu, J. N. Wang, P. L. Huang, Q. Zhang, J. T. Deng, Q. Y. Cao, J. L. Jia, J. H. Cheng, Y. P. Fang, D. Y. B. Deng and W. Y. Zhou, J. Mater. Chem. B, 2015, 3, 2206-2214.

3 P. L. Huang, B. Z. Zeng, Z. X. Mai, J. T. Deng, Y. P. Fang, W. H. Huang, H. W. Zhang, J. Y. Yuan, Y. Wei and W. Y. Zhou, J. Mater. Chem. B, 2016, 4, 46-56.

4 R. H. He, X. F. Hu, H. C. Tan, J. Feng, C. Steffi, K. Wang and W. Wang, J. Mater. Chem. B, 2015, 3, 2137-2146.

5 M. J. Chen, J. Y. Liu, Y. J. Liu, C. Guo, Z. H. Yang and H. Wu, RSC Adv., 2015, 5, 14222-14530.

6 M. J. Chen, Y. Hu, J. Zhou, Y. R. Xie, H. Wu, T. Yuan and Z. H. Yang, RSC Adv., 2016, 6, 13032-13039.

7 J. Y. Liu, C. H. Liu, Y. J. Liu, M. J. Chen, Y. Hu and Z. H. Yang, Colloids Surf., B, 2013, 109, 103-108.

8 S. D. Nath, S. Son, A. Sadiasa, Y. K. Min and B. T. Lee, Int. J. Pharm., 2013, 443, 87-94.

9 T. He, J. N. Wang, P. L. Huang, B. Z. Zeng, H. H. Li, Q. Y. Cao, S. Y. Zhang, Z. Luo, D. Y. B. Deng, H. W. Zhang and W. Y. Zhou, Colloids Surf., B, 2015, 130, 278-286.

10 S. H. Chen, Y. Chang, K. R. Lee and J. Y. Lai, J. Membr. Sci., 2014, 450, 224-234.

11 R. Zheng, H. C. Duan, J. X. Xue, Y. Liu, B. Feng, S. F. Zhao, Y. Q. Zhu, Y. Liu, A. J. He, W. J. Zhang, W. Liu, Y. L. Cao and G. D. Zhou, Biomaterials, 2014, 35, 152-164.

12 L. Y. Cheng, X. M. Sun, C. M. Hu, R. Jin, B. S. Sun, Y. M. Shi, L. Zhang, W. G. Cui and Y. G. Zhang, Acta Biomater., 2013, 9, 9461-9473.

13 A. Mahor, S. K. Prajapati, A. Verma, R. Gupta, A. K. Iyer and P. Kesharwani, J. Colloid Interface Sci., 2016, 483, 132-138.

14 C. D. Liu, Z. X. Zhang, X. Liu, X. P. Ni and J. Li, RSC Adv., 2013, 3, 25041-25049.
15 H. L. Che, M. Huo, L. Peng, T. Fang, N. Liu, L. Feng, Y. Wei and J. Y. Yuan, Angew. Chem., 2015, 127, 9062-9066.

16 J. F. Huang, J. Zhong, G. P. Chen, Z. T. Lin, Y. Q. Deng, Y. L. Liu, P. Y. Cao, B. W. Wang, Y. T. Wei, T. F. Wu, J. Yuan and G. B. Jiang, ACS Nano, 2016, 10, 6464-6473.

$17 \mathrm{Y}$. Hu, X. Y. Gu, Y. Yang, J. Huang, M. Hu, W. K. Chen,

Z. Tong and C. Y. Wang, ACS Appl. Mater. Interfaces, 2014, 6, 17166-17175.

18 A. Servant, V. Leon, D. Jasim, L. Methven, P. Limousin, E. V. F. Pacheco, M. Prato and K. Kostarelos, Adv. Healthcare Mater., 2014, 3, 1334-1343.

19 H. W. Kim, J. C. Knowles and H. E. Kim, Biomaterials, 2004, 25, 1279-1287.

20 D. Q. Chen and J. F. Sun, Polym. Chem., 2015, 6, 998-1004. 21 A. Baeza, M. Manzano, M. Colilla and M. V. Regí, Biomater. Sci., 2016, 4, 803-813.

22 T. Pengpong, P. Sangvanich, K. Sirilertmukul and N. Muangsin, Eur. J. Pharm. Biopharm., 2014, 86, 487-497.

23 M. Y. Baia and S. Z. Liu, Colloids Surf., B, 2014, 117, 346-353. 24 J. M. Yang, L. S. Zha, D. G. Yu and J. Y. Liu, Colloids Surf., B, 2013, 102, 737-743.

25 A. A. Samad, Y. Bakkour, C. Fanny, F. E. Omar, J. Coudane and B. Nottelet, Polym. Chem., 2015, 6, 5093-5102.

26 D. Chopra, L. Ray, A. Dwivedi, S. K. Tiwari, J. Singh, K. P. Singh, H. N. Kushwaha, S. Jahan, A. Pandey, S. K. Gupta, R. K. Chaturvedi, A. B. Pant, R. S. Ray and K. C. Gupta, Biomaterials, 2016, 84, 25-41.

27 S. Y. Zhai, Y. H. Ma, Y. Y. Chen, D. Li, J. Cao, Y. J. Liu, M. T. Cai, X. X. Xie, Y. W. Chen and X. L. Luo, Polym. Chem., 2014, 5, 1285-1297.

28 X. J. Zhao, S. Chen, Z. F. Lin and C. Du, Carbohydr. Polym., 2016, 148, 98-106.

29 J. M. Yang, J. H. Yang, S. C. Tsou, C. H. Ding, C. C. Hsu, K. C. Yang, C. C. Yang, K. S. Chen, S. W. Chen and J. S. Wang, Mater. Sci. Eng., C, 2016, 66, 170-177.

30 L. G. G. Mascaraque, G. Sanchez and A. L. Rubio, Carbohydr. Polym., 2016, 150, 121-130.

31 L. H. Cao, J. Luo, K. H. Tu, L. Q. Wang and H. L. Jiang, Colloids Surf., B, 2014, 115, 212-218.

32 K. Ito, A. Saito, T. Fujie, K. Nishiwaki, H. Miyazaki, M. Kinoshita, D. Saitoh, S. Ohtsubo and S. Takeoka, Acta Biomater., 2015, 24, 87-95.

33 X. H. Wu, Y. Ma, G. Q. Zhang, Y. L. Chu, J. Du, Y. Zhang, Z. Li, Y. R. Duan, Z. Y. Fan and J. Huang, Adv. Funct. Mater., 2015, 25, 2138-2146.

34 W. L. Shao, J. X. He, Q. M. Han, F. Sang, Q. Wang, L. Chen, S. Z. Cui and B. Ding, Mater. Sci. Eng., C, 2016, 67, 599-610. 35 H. Sawalha, K. Schroën and R. Boom, Chem. Eng. J., 2011, 169, 1-10.

36 H. Z. He, Y. Hong, Z. B. Gu, G. D. Liu, L. Cheng and Z. F. Li, Carbohydr. Polym., 2016, 147, 243-250.

37 X. T. Wang, Z. H. Li, Y. K. Yang, X. H. Gong, Y. G. Liao and X. L. Xie, Langmuir, 2015, 31, 5456-5463.

38 D. W. Sun, H. Zhang, X. Z. Tang and J. L. Yang, Polymer, 2016, 91, 33-40.

39 M. S. Su and J. L. Silva, Food Chem., 2006, 97, 447-451. 
40 X. Kang, C. Zhao, L. S. Yan, R. G. Qi, X. B. Jing and Z. H. Wang, Colloids Surf., B, 2016, 145, 812-819.

41 R. G. Qi, H. H. Xiao, S. H. Wu, Y. X. Li, Y. Zhang and X. B. Jing, J. Mater. Chem. B, 2015, 3, 176-179.
42 H. Q. Song, R. Wang, H. H. Xiao, H. D. Cai, W. J. Zhang, Z. G. Xie, Y. B. Huang, X. B. Jing and T. J. Liu, Eur. J. Pharm. Biopharm., 2013, 83, 63-75.

43 X. Sun, L. Y. Cheng, W. K. Zhu, C. M. Hu, R. Jin, B. S. Sun, Y. M. Shi, Y. G. Zhang and W. G. Cui, Colloids Surf., B, 2014, 115, 61-70. 